\title{
Different Methods of Fabricating Conductive Nanofibers
}

\author{
Sebnem DUZYER* \\ Department of Textile Engineering, Bursa Uludag University, Görükle Kampüsü 16059 Nilüfer, Bursa, Turkey
}

Corresponding Author: Sebnem DUZYER, sebnemduzyer@uludag.edu.tr

\begin{abstract}
Conductive nanofibers can be produced by different methods. In this study, four different methods to fabricate conductive nanofibers were explained and supported with experimental results. Nanofibers were made conductive by fabricating nanofibers from intrinsically conductive polymers (polyaniline/polyethylene oxide nanofiber production), coating the non-conductive nanofiber mat with a conductive material (copper electroplating of polyacrylonitrile nanofibers), adding a conducting material (carbon black nanoparticles, silver nanoparticles, ionic liquid) into the spinning solution, and heat treatment of the nanofiber mat (carbon and ITO nanofiber production). The surface and the electrical properties of the nanofibers were investigated. The advantages and disadvantages of the methods were discussed in detail. The results showed that conductive nanofibers can be successfully produced with different electrical conductivities depending on the method and the material.
\end{abstract}

\author{
ARTICLE HISTORY \\ Received: 25.06 .2018 \\ Accepted: 05.12.2018
}

\section{KEYWORDS}

Conductive nanofibers, electrospinning, electrically assisted solution blowing, intrinsically conductive polymers

\section{INTRODUCTION}

Due to their satisfactory electrical conductivity, flexibility, breathability, light weight and high mechanical strength; electrically conductive nanofibers have gained much attention (1). These materials have various application areas such as sensors, energy harvesting devices, fieldeffect transistors and photovoltaic devices $(2,3)$ where electrical conductivity is needed. Electrospinning is the most preferred method to fabricate electrically conductive nanofibers since it is relatively simple, versatile and allows the production from wide range of polymers $(4,5)$. Another fabrication method is electrically assistant solution blowing method, which combines solution blowing and electrospinning. Much thinner nanofibers $(20-50 \mathrm{~nm})$ can be fabricated by this method (Figure 1a,b) $(6,7)$.
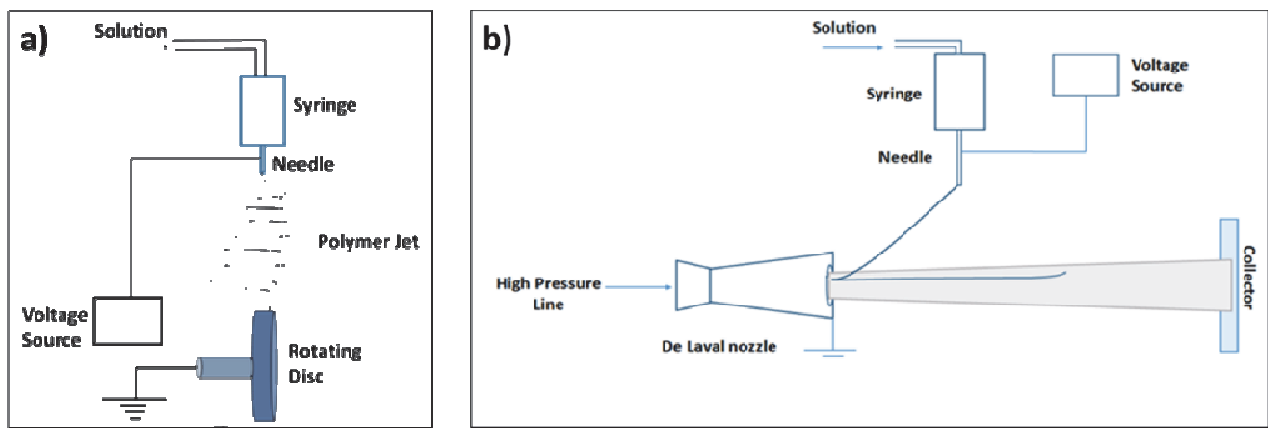

Figure 1. Schematic view of a) electrospinning and b) electrically assisted solution blowing

To cite this article: Düzyer Ş., 2018, "Different Methods of Fabricating Conductive Nanofibers" Tekstil ve Konfeksiyon, 29 (1), pp:78-85. 
There are several approaches to produce electrically conductive electrospun nanofibers. These nanofibers can be mainly produced by using intrinsically conductive polymers, coating the electrospun mat with a conductive material (e.g. copper electroplating of a mat), adding a conducting material (e.g. carbon black nanoparticles, silver nanoparticles, ionic liquid) into the spinning solution and heat treatment of the electrospun mat. Below a certain critical thickness/diameter value, current conduction is expected to increase because of the effect of confinement (1) Therefore, researchers produced nanofibers from intrinsically conductive polymers and investigated the potential of nanofibers in electrical conductivity applications and showed the enhancement of the conductivity because of their higher surface area (2).

Intrinsically conductive polymer is an organic polymer that possesses the electrical, electronic, magnetic, and optical properties of a metal while retaining the mechanical properties, processibility, etc. commonly associated with a conventional polymer. Polyaniline (PANi) is found to be the most promising because of its ease of synthesis, low cost monomer, tunable properties, and better stability compared to other intrinsically conductive polymers. However, it has low solubility in all available solvents and it is hard to process compared to other polymers. Therefore, a second polymer such as polyethylene oxide (PEO) is added to increase the spinnability of the solution. PANi nanofibers were successfully electrospun for the first time by MacDiarmid and co-workers (3). Zhang and Rutledge (8), produced PANi and PANi blend nanofibers. They used coaxial electrospinning to produce pure PANi nanofibers and reached conductivities as high as $50 \pm 30 \mathrm{~S} / \mathrm{cm}$ and 130 $\pm 40 \mathrm{~S} / \mathrm{cm}$ upon further solid state drawing. Wei et. al (9) produced electrospun core-sheath nanofibers from PANi blends. They used different carrier polymers such as poly(sulfonated styrene) (PS), polycarbonate, PMMA and PEO. Depending on the carrier, they produced electrospun conductive nanofibers with conductivities changing from $5.5 \times 10^{-14}$ to $2.4 \times 10^{-13}$ to $\mathrm{ohm}^{-1} \cdot \mathrm{cm}^{-1}$ whereas $\mathrm{Yu}$ et. al. reported that pure PANi nanofibers have conductivities ranging from 7.90 to $52.90 \mathrm{~S} / \mathrm{cm}$ (10). Poly(3,4ethylenedioxythiophene) (PEDOT) is an another member of intrinsically conductive polymers which has gained much attention especially in flexible electrode applications due to its good thermal, electrochemical and ambient stability, high conductivity, and high transparency in the p-doped state. $(11,12)$. It is commercially available in a range of properties usually in the form of poly(styrene sulfonate) (PSS) doped PEDOT (PEDOT:PSS). Zhao et al. (13) produced PEDOT:PSS/PEO nanofibers by electrospinning. They used high molecular weight $\mathrm{PEO}$ as a carrier and reached the maximum conductivity of a single electrospun fiber with a value of $35.5 \mathrm{~S} / \mathrm{cm}$. Liu et. al. (14) developed a strain sensor from PEDOT:PSS/ polyvinyl alcohol (PVA) electrospun nanofibers by encapsulating dimethylsulfoxide. With controlling the concentration of the additive dimethylsulfoxide (DMSO), the electrical conductivity of the as-spun PEDOT:PSS-PVA nanofiber network was tuned over a wide range from $4.8 \times 10^{-8}$ to $1.7 \times 10^{-5} \mathrm{~S} / \mathrm{cm}$.

Although intrinsically conductive polymers have gained a great deal of interest, processability of these polymers is challenging. They cannot be melt processed and are insoluble in most solvents. Another approach is to produce conductive polymeric composite nanofibers. In this process, conductive nanofibers are fabricated by adding a conducting component into the spinning solution. For instance, Tiwari et. al. (15) added electrically conductive carbon black nanoparticles into the spinning solution to produce permeable, flexible strain sensors. They investigated the effect of carbon black concentration on the electrical resistance of nanocomposite strips and demonstrated that fibrous nanocomposite strips with embedded carbon black nanoparticles manifest a reproducible dependence of their electrical resistance $(R)$ on their strain in uniaxial elongation. Ionic liquids have negligible vapor pressure, low toxicity, and good chemical and thermal stabilities. Moreover, they have extremely high ionic conductivity. Recently, incorporation of ionic liquids with polymers has gained interest due to their ability of improving the conductivity and promoting the electron transfer. With the addition of an ionic liquid into the spinning solution, conductive nanofibers can be fabricated. Ionic liquid-based polymers have potential application areas such as biosensors and polymer electrolytes. Lu et. al. produced polystyrene-ionic liquid composite nanofibers and films. They entrapped ionic liquid in the polymer by electrospinning. The samples showed both superhydrophobicity and conductivity which indicated ionic liquid-based composite nanofibers can be an alternative candidate for the functionalization of surfaces (16).

Electrically conductive nanofibers can be also produced by coating the surfaces with metals such as copper and silver. Electroplating is a widely used technique to deposit metals on nanofiber surfaces. However, studies on the coating of nanofibers by electroplating are rare. Sinha-Ray et al. developed a new method of electroplating of electrospun nanofiber mats and investigated the cooling capabilities of the electrospun nanofiber mats coated metallic by electroplating. They showed that non-conductive electrospun nanofibers can be successfully coated by copper, silver, nickel and gold by electroplating (17).

Another method to fabricate conductive nanofibers is the heat treatment of electrospun precursors. Carbon and indium tin oxide (ITO) nanofiber fabrications are two methods that involve heat treatment. Carbon nanofibers are one-dimensional structures which possess high mechanical strength, great stiffness, excellent electrical and thermal conductivity, good fatigue and corrosion resistance. In the literature, there are many researches about conductive carbon nanofibers. For instance, Wang et. al. produced PAN-based carbon nanofibers and measured the electrical conductivity as $490 \mathrm{~S} / \mathrm{m}$ (18). Zhi et al. produced highly conductive electrospun carbon nanofiber/manganese dioxide coaxial cables for energy and supercapasitor applications. They used highly conductive carbon nanofibers as the support backbone for manganese dioxide for supercapacitor electrode and found out that the carbon nanofibers $/ \mathrm{MnO}_{2}$ coaxial nanostructure shows enhanced specific capacitance (19). An alternative method of fabricating carbon nanofibers is heat treatment of electrospun precursors. Heat treatment is a process that converts the polyacrilonitrile (PAN) nanofiber precursors to carbon nanofibers. PAN is the most used polymer for the fabrication of precursors because of its easy carbonization process. The heat treatment process of PAN involves stabilization in oxygen atmosphere $\left(200-300{ }^{\circ} \mathrm{C}\right)$, carbonization $\left(\approx 1000{ }^{\circ} \mathrm{C}\right)$ in an inert atmosphere (usually 
nitrogen), and graphitization $\left(>2000{ }^{\circ} \mathrm{C}\right)$ of the precursor under controlled conditions (20-22). ITO nanofibers, which have unique properties of high transmittance, low resistivity and excellent adhesion to substrates, can be also produced by electrospinning. In this process, the ITO nanofibers are fabricated from a precursor polymer solution which also includes another polymer (e.g. PEO, polyvinyl pyrrolidone (PVP)). The role of the other polymer is to increase the viscosity and improve the spinnability of the solution. The electrospinning process is followed by the heat treatment of the electrospun mat where other polymer is selectively removed. Also, the proper crystal structure is obtained by heat treatment $(23,24)$. Xu and Shi produced ITO nanofibers by using PVP as precursor for gas sensing applications. (23). Munir et al. successfully produced electrically conductive and optically transparent ITO nanofibers by electrospinning. They achieved a minimum sheet resistance of $1.2 \times 105 / \Omega / s q$ at a deposition time of $20 \mathrm{~min}(24)$.

This paper mainly describes the conductive nanofiber production methods. The paper gives brief information about fabricating conductive nanofibers from intrinsically conductive polymers, electroplating of non-conductive nanofiber mats, adding a conductive compound to the nanofiber and heat treatment of the mat. These methods are explained in detail and supported by the experimental results.

\section{MATERIALS AND METHODS}

In this study, some of the materials were used more than one method. Therefore, in this section all materials were given without any classification. Polyaniline (PANi) (Mw: $15,000 \mathrm{Da})$, camphorsulphonic acid (HCSA), polyethylene oxide (PEO) (Mw: 2,000 kDa), Poly acrylonitrile (PAN) (Mw: $150 \mathrm{kDa}$ ), indium (III) nitrate hydrate, tin (II) acetate, acetic acid, acetone, ethanol, N,N-dimethylformamide (DMF) anhydrous, $99.8 \%$ (Aldrich), dichloromethane (DCM) anhydrous, $\geq 99.8 \%$, chloroform, silver nitrate $\left(\mathrm{AgNO}_{3}\right)$, Sodium borohydride $\left(\mathrm{NaBH}_{4}\right)$, ionic liquid $\left(\mathrm{ElmBF}_{4}\right)$, polyvinylpyrrolidone (PVP) (Mw:40 kDa), ethanol, acetic acid, Poly(3,4-ethylenedioxythiophene):poly (styrenesulfonate) (PEDOT:PSS) (1.1\% in water), Polycaprolactone (PCL) (Mn: $80 \mathrm{kDa}$ ), were purchased from Sigma-Aldrich Inc. and carbon black (CB2000) grade was purchased from Cabot Corporation. All chemicals were used without further purification.

Fabrication of PANi:/PEO blend nanofibers: In this study, $0.4 \mathrm{~g}$ PANi and $0.05 \mathrm{~g}$ PEO were dissolved in $7.95 \mathrm{~g}$ chloroform. PANi was doped with $1.6 \mathrm{~g}$ camphorsulphonic acid (HCSA). The procedure was as follows: Pure PANi is black and not conductive before doping process. Therefore, it needs to be doped with HCSA in chloroform. After doping, the color of the solution becomes green. In this study, first, HCSA was dissolved in chloroform. After dissolution, PANi was added and stirred at room temperature for $1 \mathrm{~h}$. Since the solubility of PANi is very low and the polymer solution is hard to electrospin, PEO was used as a second polymer. PEO and DMF were added to the solution and kept stirring for $6 \mathrm{~h}$ at $45^{\circ} \mathrm{C}$. In the literature, researchers filtered the PANi solution before making fibers. In this study, two groups of PANi/PEO solutions were prepared. In order to see the effect of filtration on fiber mat conductivity one of them was filtered by using a filter paper (Whatman-Grade 602h).
PANi/PEO nanofibers were produced by electrospinning method with a polymer flow rate of $2 \mathrm{ml} / \mathrm{h}$. and a voltage of 7 $\mathrm{kV}$. The fibers were collected on a glass slide placed on a rotating disc. The edges of the glass slide were painted with conductive carbon paint to measure the conductivities of the mats. Since the sample produced from filtered solution was not conductive, the study was focused on only unfiltered one. Therefore, five samples from unfiltered solutions with different gap lengths were prepared in order to see the effect of gap length on conductivity.

\section{Fabrication of PEDOT:PSS/PEO blend nanofibers:} PEDOT:PSS/PEO solutions were prepared by dissolving $0.06 \mathrm{~g}$ of PEO in $3.94 \mathrm{~g}$ of DMF. The solution was stirred on a hot plate at $75^{\circ} \mathrm{C}$ for $12 \mathrm{~h}$. After it was completely dissolved, $6 \mathrm{~g}$ of PEDOT:PSS was added into the solution and stirred on the hot plate at $75^{\circ} \mathrm{C}$ for another $3 \mathrm{~h}$. PEO/PEDOT:PSS nanofibers were prepared by electrically assisted subsonic solution blowing (6) since much thinner fibers can be produced with this method from polymer solutions with lower viscosities compared to electrospinning. In this study, $0.68 \mathrm{kV}$ voltage was applied between the droplet of the polymer solution and the air nozzle. The polymer solution was electrospun from a plastic syringe with an internal diameter of about $18 \mathrm{G}$ with a flow rate of 0.7 $\mathrm{mL} / \mathrm{h}$ and blown with an air with a speed of $10 \mathrm{psi}$. The fibers were collected on a glass slide with a gap of $5 \mathrm{~mm}$. The glass slide was mounted on a rotating plate with a speed of $30 \mathrm{rpm}$. Electrically assisted subsonic solution blowing was conducted at room temperature for 2 minutes.

Fabrication of PCL/Carbon Black nanofibers: In the first step, $2 \mathrm{~g}$ of PCL was dissolved in $4.8 \mathrm{~g}$ of DMF and $3.2 \mathrm{~g}$ of $\mathrm{DCM}$ and stirred on a hot plate at $45{ }^{\circ} \mathrm{C}$ for $2 \mathrm{~h}$. Separately, $0.2 \mathrm{~g}$ of carbon black was added to a $5.8 \mathrm{~g}$ of DMF/ DCM $(60: 40)$ mixture. The mixture was sonicated by a probe sonicator (QSONICA, $500 \mathrm{~Hz}$ ). Afterwards, $4 \mathrm{~g}$ of PCL solution and $6 \mathrm{~g}$ of carbon black mixture were mixed together and stirred on a hot plate at $45{ }^{\circ} \mathrm{C}$ for another $4 \mathrm{~h}$. The PCL/carbon black nanofibers were fabricated by electrospinning with an electric field of $0.6 \mathrm{kV} / \mathrm{cm}$. The flow rate was $0.7 \mathrm{~mL} / \mathrm{h}$ and the inner diameter of the needle was $18 \mathrm{G}$. The fibers were collected on a glass slide with a gap of $5 \mathrm{~mm}$. The glass slide was mounted on a rotating disc with a speed of $200 \mathrm{rpm}$. The electrospinning was conducted at room temperature for 10 minutes. After electrospinning, the samples were kept on the hot plate at $45^{\circ} \mathrm{C}$ for $24 \mathrm{~h}$.

\section{Fabrication of PAN/ silver nitrate $\left(\mathrm{AgNO}_{3}\right)$ nanofibers: In} order to prepare $\mathrm{PAN} / \mathrm{AgNO}_{3}$ nanofibers, $0.8 \mathrm{~g}$ PAN was dissolved in $5.86 \mathrm{~g} \mathrm{DMF}$ and kept on a hot plate at $75{ }^{\circ} \mathrm{C}$ until it was dissolved completely. Separately, $0.4 \mathrm{~g} \mathrm{AgNO}_{3}$ in $2.94 \mathrm{~g}$ DMF was prepared and sonicated for 5 minutes. Afterwards, $\mathrm{AgNO}_{3} / \mathrm{DMF}$ solution was added to PAN solution and left on the $35^{\circ} \mathrm{C}$ hot plate for $1 \mathrm{~h}$. The fibers were fabricated by electrospinning. The flow rate was 0.3 $\mathrm{mL} / \mathrm{h}$ and the voltage was $15 \mathrm{kV}$. After electrospinning, the nanofibers were treated with $\mathrm{NaBH}_{4}$ (1\% wt. in water) in order to achieve a reduction process of $\mathrm{AgNO}_{3}$ and obtain Ag.

Fabrication of PAN/ionic liquid nanofibers: PAN/ionic liquid solution were prepared by dissolving $8 \%$ wt. PAN in DMF. The solution was kept on a hot plate at $75{ }^{\circ} \mathrm{C}$ until it was completely dissolved. An ionic liquid $\left(E \mathrm{ImBF}_{4}\right)$ of $0,4 \mathrm{~g}$ 
was added to the $8 \%$ wt. PAN solution and sonicated for 30 $\mathrm{min}$. The fibers were fabricated by electrospinning. The flow rate was $0.3 \mathrm{~mL} / \mathrm{h}$ and the voltage was $15 \mathrm{kV}$.

Fabrication of Conductive Nanofibers by Coating with a Conductive Material: Non-conductive nanofiber mats can be made conductive by coating the mat with a conductive material. In this study, PAN nanofiber mat was used as a template for coating with copper. In order to prepare PAN nanofibers, $8 \%$ wt. PAN was dissolved in DMF and kept on a hot plate at $75{ }^{\circ} \mathrm{C}$ until it was dissolved completely. PAN nanofibers were produced by electrospinning. The flow rate was $0.3 \mathrm{~mL} / \mathrm{h}$ and the voltage was $15 \mathrm{kV}$. After electrospinning, the fiber mat was coated with copper by electroplating. For copper electroplating; sulfuric acid (5 g), hydrochloric acid $(0.5 \mathrm{~g})$, copper sulfate $(16 \mathrm{~g})$, and formaldehyde $(10 \mathrm{~g})$ were mixed with $100 \mathrm{~mL}$ of deionized water to prepare a copper plating solution. Voltage was kept between $0-1 \mathrm{~V}$ for $15 \mathrm{~s}$ to form a fine coating. Plating was conducted for both sides of the sample. After electroplating, the copper-plated nanofiber mat was immersed into $10 \%$ formaldehyde solution for $5 \mathrm{~min}$ and then rinsed twice with deionized water.

Fabrication of Carbon Nanofibers: Carbon nanofibers were produced from PAN nanofiber precursors. PAN nanofiber precursor was electrospun with the same solution and spinning parameters as PAN nanofiber mats used for copper electroplating. After electrospinning, the PAN nanofiber mat was heated to give carbon nanofibers. The process was started at room temperature to $300{ }^{\circ} \mathrm{C}$ in air, and continued to $1100{ }^{\circ} \mathrm{C}$ in nitrogen atmosphere.

Fabrication of ITO Nanofibers: ITO/PVP blend nanofibers were produced by electrospinning. PVP was added to the spinning solution to increase the viscosity and the spinnability. After electrospinning, PVP was removed by heat treatment and pure ITO nanofibers were obtained. _For the preparation of ITO solution; $2.04 \mathrm{~g}$ indium (III) nitrate hydrate and $0.16 \mathrm{~g}$ tin (II) acetate were mixed in $5.6 \mathrm{~g}$ water and sonicated for $30 \mathrm{~min}$. Separately, $2 \mathrm{~g}$ of PVP was dissolved in 8 of ethanol and kept on a hot plate at $40^{\circ} \mathrm{C}$ for $2 \mathrm{~h}$. Afterwards, ITO solution and PVP solution were mixed together and $2.2 \mathrm{~g}$ of acetic acid was added. Then, the mixture was stirred on a hot plate at $40^{\circ} \mathrm{C}$ for another $2 \mathrm{~h}$. The electrospinning parameters were as follows: Applied voltage $14 \mathrm{kV}$, flow rate $1.2 \mathrm{~mL} / \mathrm{h}$, needle diameter $18 \mathrm{G}$ and the distance $15 \mathrm{~cm}$. Finally, the electrospun fiber mat was treated at $400{ }^{\circ} \mathrm{C}$ in open air for the calcination of ITO and the removal of PVP.

Imaging of the Nanofibers: Thickness of the nanofibers and the electrospun mats were calculated by a light microscope (Olympus BX51). Three measurements were carried out and average values were calculated for each sample. The morphology of the electrospun fibers was examined using the same light microscope. For more detailed examination a field emission scanning electron microscope (JEOL JSM 6320F, RRC- UIC) was used for some of the samples. Energy Dispersive X-Ray Spectroscopy (EDX) analyses were carried out for the heat treated PAN nanofibers to confirm the carbonization. It was also conducted for ITO nanofibers if PVP was removed and ITO fibers were successfully prepared.
Conductivities of the Nanofibers: Resistance of the samples were measured by a Mastech multimeter and conductivities $(\sigma)$ were calculated as follows:

$$
R=\rho \frac{l}{A} \ldots \ldots \ldots \ldots \ldots(1) \text { and } \sigma=\frac{1}{\rho} .
$$

Where, $\mathrm{R}$ is the electrical resistance of the sample (ohms, $\Omega), \rho$ is the resistivity of the sample $(\Omega . \mathrm{cm}), \ell$ is the length of the sample $(\mathrm{cm}), A$ is the cross-sectional area of the sample $\left(\mathrm{cm}^{2}\right), \sigma$, is the conductivity, defined as the inverse of resistivity. Conductivity has SI units of Siemens per centimeter $(\mathrm{S} / \mathrm{cm})$.

* All the fabrications and characterizations were conducted in Multiscale Mechanics and Nanotechnology Laboratory, University of Illinois at Chicago, USA.

\section{RESULTS AND DISCUSSION}

PANi:/PEO blend nanofibers: Light microscope images of electrospun PANi/PEO blend nanofibers showed that, the fibers were entangled and PANi was not distributed uniformly along the fiber (Figure 2a,b).
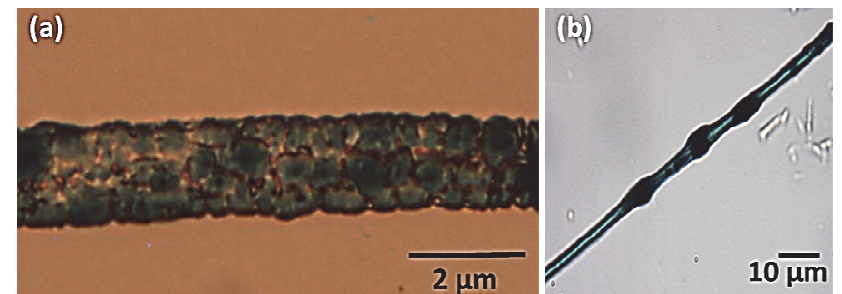

Figure 2. Single fiber image of unfiltered PANi/PEO electrospun fiber a) PANi distribution in the fiber, b) PANi chunks inside the fiber.

Small beads were observed on the surface of PANi/PEO electrospun fibers due to the PANi chunks in the spinning solution (Figure $3 b$ ). Fibers produced from unfiltered solutions had diameters around $1 \mu \mathrm{m}$, whereas fibers produced from filtered solutions had larger diameters ( $\approx 2$ $\mu \mathrm{m})$. The samples produced from the filtered solution does not have chunks and also they are parallel aligned (Figure $3 a$ ). When conductivities of the samples produced from unfiltered and filtered solutions were measured, it was seen that the samples produced from filtered solutions are not conductive. This may be due the loss of PANi during the filtration of the spinning solution. As a result, the fiber mat did not show any conductivity. On the other hand, fibers produced from unfiltered solution showed electrical conductivity indicating that they contain a percolative network of PANi chunks (Table 1). With the increasing gap distance, the conductivity values tend to decrease (Table 1). Although researchers reported that pure PANi nanofibers have conductivities ranging from 7.90 to $52.90 \mathrm{~S} / \mathrm{cm}$ (10), the results of this study are still comparable with the results of blend PANi/PEO nanofibers. Wei et al. (9) produced PANi/PEO blend nanofibers and measured the conductivity as $2.4 \times 10^{-13} \mathrm{~S} / \mathrm{cm}$ where the conductivies of the fibers produced in this study ranged from $0.137 \times 10^{-3}$ to $0.545 \mathrm{x}$ $10^{-3} \mathrm{~S} / \mathrm{cm}$ depending on the gap distance. 

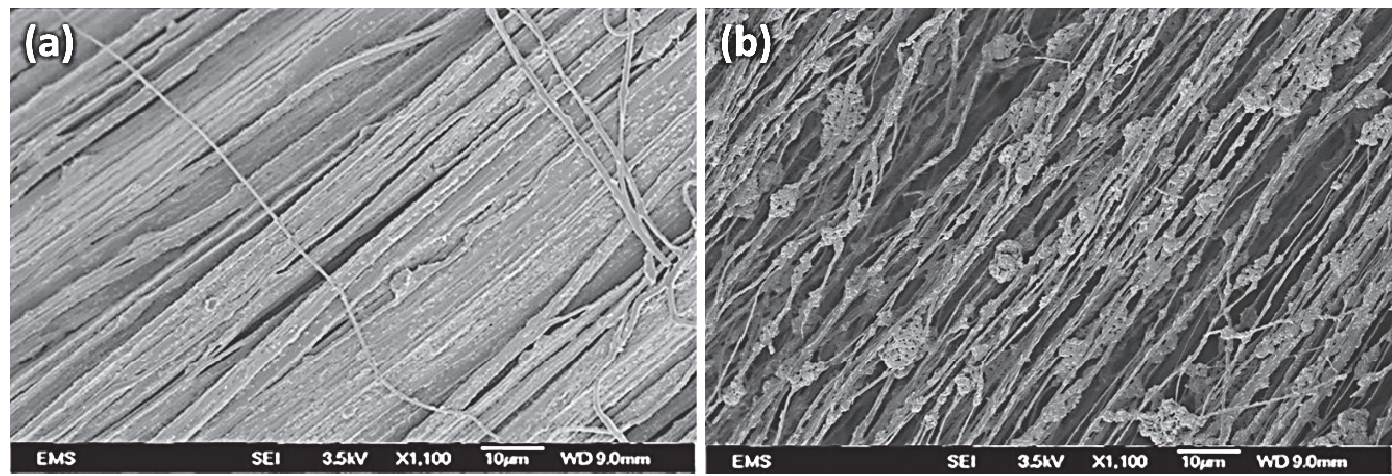

Figure 3. SEM images of PANi/PEO nanofibers produced from a) unfiltered solution, b) filtered solution
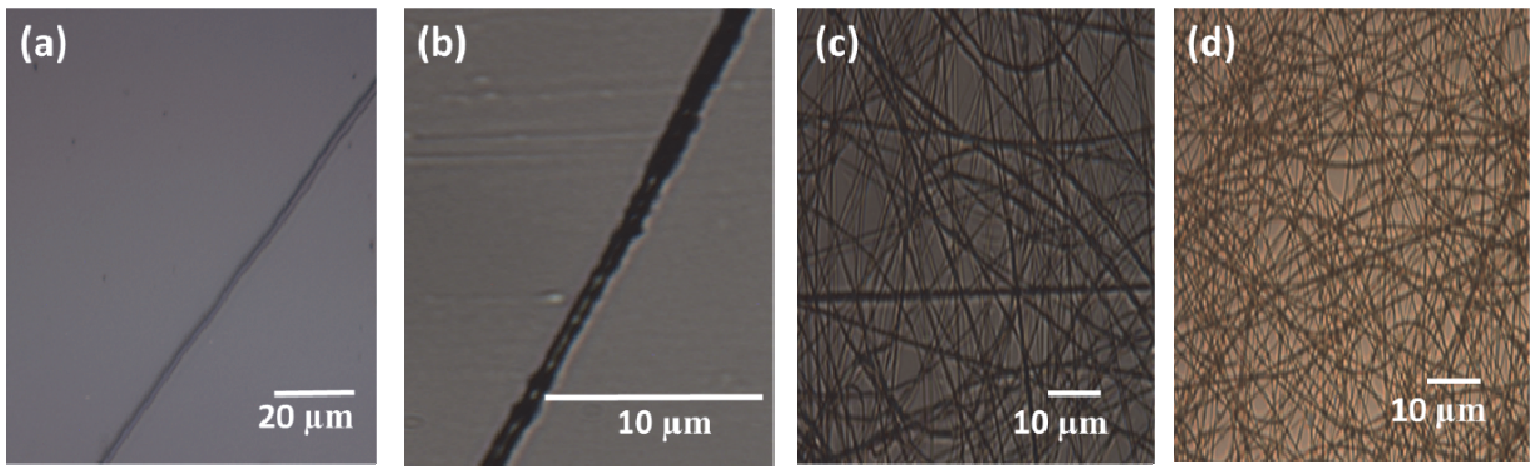

Figure 4. Light microscope images of a) single PEO/PEDOT:PSS nanofiber, b) single PCL/carbon black nanofiber, c) $\mathrm{PAN}^{\mathrm{AgNO}} \mathrm{A}_{3}$ nanofibers, d) PAN/ionic liquid fibers,

\begin{abstract}
PEDOT:PSS/PEO blend nanofibers: PEDOT:PSS/PEO fibers had diameters around $\approx 100 \mathrm{~nm}$ (Figure $4 \mathrm{a}$ ). These fibers were fabricated by electrically assisted solution blowing. The additional stretching caused by the aerodynamical forces, leads to much thinner fibers compared to electrospinning. The fibers had smooth surfaces since the polymer blend was a homogeneous dispersion. The nanofiber mat showed an electrical conductivity of $19.1 \mathrm{~S} / \mathrm{cm}$ which is higher than most of the reported values for PEDOT:PSS blend nanofibers (14). Also, the conductivity of PEDOT:PSS/PEO is very high compared to other conductive nanofibers. This result indicates that PEDOT:PSS/PEO blend nanofibers can be a very good candidate in sensor applications.
\end{abstract}

PCL/carbon black nanofibers: Figure 4b shows the light microscope image of a single PCL/carbon black nanofiber. It can be seen that PCL/carbon black nanofibers are covered with carbon black, the fiber surface was not smooth and the fibers had diameters in the order of $1 \mu \mathrm{m}$. This is mainly because of the carbon black chunks. Carbon black chunks were in $\approx 1 \mu \mathrm{m}$ in size and the PCL/carbon black was a coarse suspension with large chunks of carbon black. The fiber mat showed an electrical conductivity of $0.235 \times 10^{-3}$ $\mathrm{S} / \mathrm{cm}$ indicating that conductive nanofibers were successfully produced. In order to enhance the conductivity of the nanofibers, carbon black amount in the spinning solution can be increased.

PAN/AgNO 3 and PAN/ionic liquid nanofibers: In this study, PAN nanofibers were fabricated by electrospinning with the addition of silver nitrate $\left(\mathrm{AgNO}_{3}\right)$ or an ionic liquid into the spinning solution. The fibers were successfully electrospun from both solutions (Figure 4c,d). Electrically conductive fibers with diameters around $800 \mathrm{~nm}$ were fabricated in both cases. The conductivity results are comparable with the literature. Lu et. al. (16) prepared P. ionic liquid fibers with an electrical conductivity of $3.2 \times 10^{-4}$ $\mathrm{S} / \mathrm{cm}$. In this study, PAN/ionic liquid fiber mat with an electrical conductivity of $1.46 \times 10^{-3} \mathrm{~S} / \mathrm{cm}$ was produced. Also, an electrical conductivity of $0.95 \times 10^{-3} \mathrm{~S} / \mathrm{cm}$ was obtained for the PAN/ $\mathrm{AgNO}_{3}$ fiber mat (Table 1).

Copper Electroplated PAN Nanofibers: Non-conductive nanofiber mats can be made conductive by coating the mat with a conductive material. In this study, electrospun PAN nanofibers with a diameter around $800 \mathrm{~nm}$ was used as a template for coating with copper (Figure 5a). Figure $5 b$ shows the copper plated PAN nanofibers. The color change and the increase in diameter show that copper is coated on the fiber surface. Diameters of the coated fibers were measured around $5 \mu \mathrm{m}$. The fiber mat had an electrical conductivity of $2.13 \times 10^{-3} \mathrm{~S} / \mathrm{cm}$. Although this value is much lower than pure copper $\left(\rho_{\mathrm{cu}}=58.5 \times 106 \mathrm{~S} / \mathrm{m}(25)\right)$, it is higher than the conductivity of other conductive nanofibers such as PANi/PEO blend fibers, $\mathrm{PAN} / \mathrm{AgNO}_{3}$ fibers etc. The results show that conductive nanofibers can be successfully fabricated by coating with a conductive material.

Carbon Nanofibers: Carbon nanofibers were obtained by the carbonization of PAN nanofibers. The diameters of the carbon nanofibers were measured around $600 \mathrm{~nm}$ (Figure $6)$. The elemental analysis revealed the presence of $C$ on the surface. The elemental ratio of $C$ and $O$ were 99.48 and $0.52 \%$ respectively. That means PAN nanofibers were successfully carbonized. The fiber mat had an electrical conductivity of $666.67 \mathrm{~S} / \mathrm{cm}$ meaning that these nanofibers have excellent electrical conductivity (Table 1). 


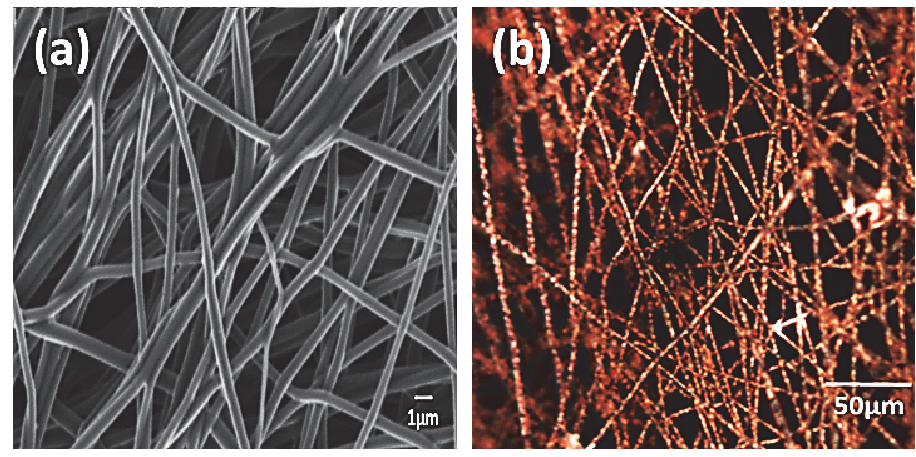

Figure 5. a) SEM image of untreated PAN nanofibers, b) Light microscope images of copper electroplated PAN nanofibers
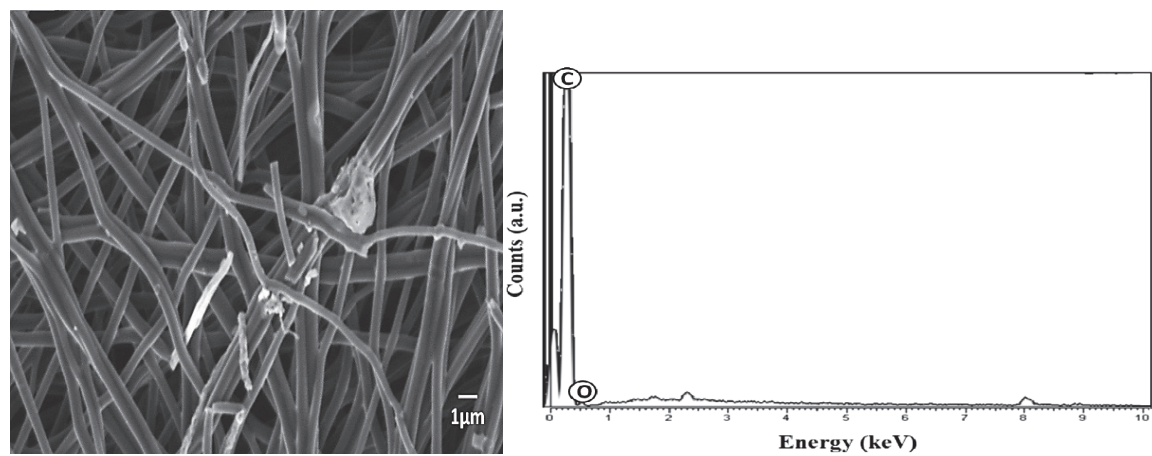

Figure 6. From left to right, SEM image and EDX spectrum of the heat treated PAN (carbon) nanofibers, respectively

ITO Nanofibers: Since the fiber mat was treated with heat for the removal of PVP and the calcination of ITO, the fiber mat shrank around $20 \%$ (Figure $7 a, b$ ). The fibers had diameters around $100 \mathrm{~nm}$ after heat treatment. After the removal of PVP, nanofibers remained as continuous structures (Figure 7c). The elemental analysis showed that PVP was removed and ITO fibers were prepared. The elemental ratio of $\mathrm{C}, \mathrm{O}$, In and $\mathrm{Sn}$ were $5.32,33.97,56.49$, $4.21 \%$ respectively. The conductivity of ITO is due to the oxygen vacancies and the defects. The preparation conditions such as the operational procedures, annealing ambient (time, temperature atmosphere and pressure), composition, type and quantity of the dopant and heat treatment method also affect the level of the conducting carrier concentration and oxygen vacancies $(23,26)$. In this study, the fiber mat had an electrical conductivity of 0.426
S/cm which makes ITO nanofibers a good candidate for technical applications.
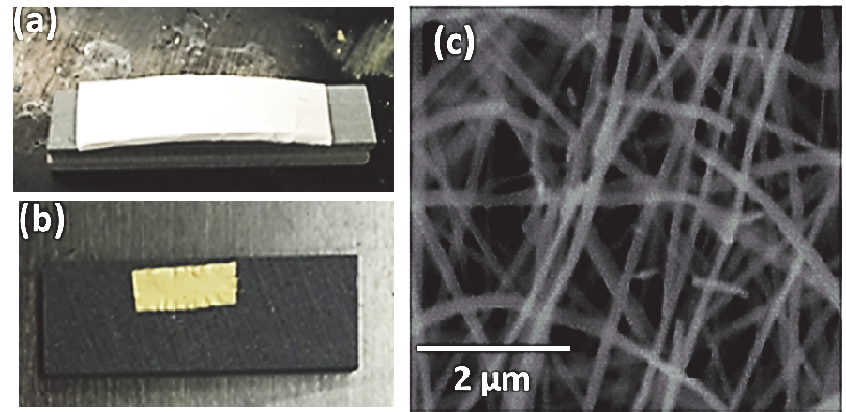

Figure 7. a) ITO nanofiber mat before heat treatment, b) ITO nanofiber mat after heat treatment, c) SEM image of ITO nanofibers after heat treatment.

Table 1. Electrical properties of the nanofiber mats

\begin{tabular}{|c|c|c|c|c|c|}
\hline Material & $\begin{array}{c}\text { Resistance } \\
(\mathbf{M} \mathbf{\Omega})\end{array}$ & $\begin{array}{c}\text { Width } \\
(\mathbf{m m})\end{array}$ & $\begin{array}{c}\text { Thickness } \\
(\boldsymbol{\mu m})\end{array}$ & $\begin{array}{c}\text { Length } \\
(\mathbf{m m})\end{array}$ & $\begin{array}{c}\text { Conductivity }(\boldsymbol{\sigma}) \\
(\mathbf{S} / \mathbf{c m})\end{array}$ \\
\hline PANi/PEO (filtered) & - & 25 & $8 \pm 0.58$ & 10 & - \\
\hline PANi/PEO (unfiltered) & 1.1 & 25 & $4 \pm 1.15$ & 6 & $0.545 \times 10^{-3}$ \\
\hline PANi/PEO (unfiltered) & 2.7 & 25 & $3 \pm 0.58$ & 10 & $0.494 \times 10^{-3}$ \\
\hline PANi/PEO (unfiltered) & 2.9 & 25 & $6 \pm 1.53$ & 16 & $0.368 \times 10^{-3}$ \\
\hline PANi/PEO (unfiltered) & 3.2 & 25 & $10 \pm 2.52$ & 26 & $0.325 \times 10^{-3}$ \\
\hline PANi/PEO (unfiltered) & 20.4 & 25 & $6 \pm 2.08$ & 42 & $0.137 \times 10^{-3}$ \\
\hline PEDOT:PSS (2 min) & $34.9 \times 10^{-6}$ & 25 & $3 \pm 0.58$ & 5 & 19.1 \\
\hline PCL/carbon black (10 min) & 0.12 & 25 & $71 \pm 6.24$ & 5 & $0.235 \times 10^{-3}$ \\
\hline PAN/AgNO & 0.7 & 15 & $10 \pm 2.89$ & 10 & $0.95 \times 10^{-3}$ \\
\hline PAN/ionic liquid & 0.2 & 7 & $98 \pm 5.69$ & 20 & $1.46 \times 10^{-3}$ \\
\hline Copper-plated PAN & 0.01 & 30 & $470 \pm 9.17$ & 30 & $2.13 \times 10^{-3}$ \\
\hline Carbon Nanofibers & $45 \times 10^{-6}$ & 5 & $1 \pm 0.07$ & 15 & 666.67 \\
\hline ITO & 0.012 & 4 & $44 \pm 3.06$ & 9 & 0.426 \\
\hline
\end{tabular}




\section{CONCLUSION}

In this study four different methods were investigated to produce conductive nanofibers. PANi/PEO and PEDOT:PSS/PEO blend nanofibers were fabricated from intrinsically conductive polymers by electrospinning and electrically assisted solution blowing methods, respectively. The electrospun PAN nanofiber mat was coated with copper by electroplating. Conductive PCL/carbon black, $\mathrm{PAN} / \mathrm{AgNO}_{3}$ and $\mathrm{PAN} /$ ionic liquid electrospun nanofibers were produced with the addition of a conductive material into the spinning solution. Conductive carbon and ITO electrospun nanofibers were produced by heat treatment. The surface and the electrical properties of the produced nanofibers were investigated. Conductive nanofibers were successfully produced. Each nanofiber mat showed different surface and electrical characteristics. When the methods were compared to each other in terms of cost, facility, convenience and conductivity, it can be seen that each method has its own advantages and disadvantages. Although intrinsically polymers are conductive and flexible with light-weight; they are expensive and hard to make nanofibers on their own. With the addition of a second polymer into the spinning solution, these nanofibers can be produced. However, this leads to a decrease in electrical conductivities. In this study PANi/PEO nanofibers showed relatively low electrical conductivities, whereas PEDOT:PSS/PEO nanofibers showed higher values. This indicates that polymer type is a significant parameter and proper polymer type should be chosen depending on the application area. Adding conductive components into the spinning solution is cost efficient and the blend nanofibers had relatively low conductivities but comparable with PANi/PEO nanofibers. It should be noted that the cost and the conductivity will be changed depending on the particle type, size and distribution. Electroplating is another alternative to produce conductive surfaces as it is easy, fast and allows to produce conductive surfaces from nonconductive nanofibers. However, it adds an extra step and usage of lots of chemicals. In this study electroplated PAN nanofibers showed higher conductivities compared to PANi/PEO, PCL/carbon black, $\mathrm{PAN} / \mathrm{AgNO}_{3}, \mathrm{PAN} /$ ionic liquid nanofibers. Electrospun conductive carbon and ITO nanofibers were obtained after heat treatments. During heat treatments, very high temperature and different atmospheres are needed. Carbon nanofibers had the highest electrical conductivity among all the nanofibers. These nanofibers can be chosen where extremely high conductivity is needed. Although ITO showed lower conductivity compared to carbon nanofibers, they are still very conductive. However, raw materials of ITO are rare, expensive and the nanofibers became brittle after heat treatments. Considering these properties, appropriate material and method should be chosen, depending on the desired application area.

\section{ACKNOWLEDGMENTS}

This study was a part of the author's postdoctoral project. The author is grateful to Prof. Alexander L. Yarin, Sumit Sinha Ray and Suman Sinha Ray for their fruitful contributions to the study. The study was supported by 2219 International Post-Doctoral Research Fellowship Programme (2015/1) of the Scientific and Technological Council of Turkey (TUBITAK).

\section{REFERENCES}

1. Ko, F, Aufy,A,Macdiarmid A, (Edited X.T. Ko, F.K., Aufy, A.Lam, H., "Electrostatistically generated nanofibers for wearable electronics" in "Wearable electronics and photonics." CRC Press, 2005.

2. Aussawasathien,L.,D., Dong, J-H., Dai, “Electrospun polymer nanofiber sensors” Synth. Met., 154:37-40, 2005.

3. MacDiarmid, A.G.,'Synthetic Metals’: A Novel Role for Organic Polymers (Nobel Lecture)” Angew. Chemie Int. Ed., 40 (14):2581-2590, 2001.

4. Thavasi, V.,G. Singh, S. Ramakrishna, "Electrospun nanofibers in energy and environmental applications” Energy Environ. Sci., vol. 1, no. 2, p. 205 , 2008.

5. Duzyer, S., A. Hockenberger, and E. Zussman, “Characterization of solvent-spun polyester nanofibers” J. Appl. Polym. Sci., 120 (2): $759-769,2011$.

6. Sinha-Ray, S., M. W. Lee, S. Sinha-Ray, S. An, B. Pourdeyhimi, S. S. Yoon, A. L. Yarin, "Supersonic nanoblowing: a new ultra-stiff phase of nylon 6 in 20-50 nm confinement" J. Mater. Chem. C, 1 (21): 3491, 2013.

7. Lee, B.,M.W., Yoon, S.G., Yarin, A.L., Sinha-Ray, S., Pourdeyhimi, “US20140234457 A1,” 2014.

8. Zhang, Y.,G. C. Rutledge, "Electrical conductivity of electrospun polyaniline and polyaniline-blend fibers and mats" Macromolecules, 45(10): 4238-4246, 2012

9. Wei, M., J. Lee, B. Kang, J. Mead, "Preparation of Core-Sheath Nanofibers from Conducting Polymer Blends" Macromol. Rapid Commun., 26(14): 11271132, 2005.

10. Yu, QZ.,M.M. Shi, M. Deng, M. Wang, H.Z. Chen, "Morphology and conductivity of polyaniline sub-micron fibers prepared by electrospinning" Mater. Sci. Eng. B Solid-State Mater. Adv. Technol., 150(1):70-76, 2008.

11. Baik, W., W. Luan, R. H. Zhao, S. Koo, K. S. Kim, "Synthesis of highly conductive poly(3,4-ethylenedioxythiophene) fiber by simple chemical polymerization" Synth. Met.,159(13):1244-1246, 2009.

12. Latessa, G., F. Brunetti, A. Reale, G. Saggio, A. Di Carlo, "Piezoresistive behaviour of flexible PEDOT:PSS based sensors" Sensors Actuators, B Chem., 139 (2): 304-309, 2009.

13. Zhao, W., B. Yalcin, M. Cakmak, "Dynamic assembly of electrically conductive PEDOT:PSS nanofibers in electrospinning process studied by high speed video" Synth. Met., 203:107-116, 2015.

14. Liu, N.,G.Fang, J.Wan, H.Zhou,H. Long, X. Zhao, "Electrospun PEDOT:PSS-PVA nanofiber based ultrahigh-strain sensors with controllable electrical conductivity" J. Mater. Chem.,21(47). 18962, 2011.

15. Tiwari, M.K., A. L. Yarin, C. M. Megaridis, "Electrospun fibrous nanocomposites as permeable, flexible strain sensors" J. Appl. Phys., 103 (4): 044305 , 2008. 
16. Lu, X., J. Zhou, Y. Zhao, Y. Qiu, J. Li, "Room Temperature Ionic Liquid Based Polystyrene Nanofibers with Superhydrophobicity and Conductivity Produced by Electrospinning" Chem. Mater., 20(10): 3420-3424, 2008.

17. Sinha-Ray, S., Y. Zhang, A. L. Yarin, "Thorny devil nanotextured fibers: the way to cooling rates on the order of $1 \mathrm{~kW} / \mathrm{cm} 2$ " Langmuir, 27(1): 215-226, 2011.

18. Wang, Y., S. Serrano, J.J. Santiago-Aviles, "Conductivity measurement of electrospun PAN-nased carbon nanofibers" Journal of Material Science Letters, 21:1055-1057, 2002.

19. Zhi, M., A. Manivannan, F. Meng, N. Wu, "Highly conductive electrospun carbon nanofiber/MnO ${ }_{2}$ coaxial nano-cables for high energy and power density supercapacitors, Journal of Power Sources, 208:345-353, 2012

20. Dalton,S., F.Heatley, P.M. Budd, "Thermal stabilization of polyacrylonitrile fibres" Polymer, 40:553-43, 1999.

21. Ismar, E., A.S. Sarac, "Oxidation of polyacrylonitrile nanofiber webs as a precursor for carbon nanofiber: aligned and non-aligned nanofibers" Polymer Bulletin, 75: 485-499, 2018.

22. Rahaman, MSA., A. F. Ismail, A. Mustafa, "A review of heat treatment on polyacrylonitrile fiber" Polymer Degradation and Stability, 92(8):1421-1432, 2007.

23. Xu, S., Y. Shi, "Low temperature high sensor response nano gas sensor using ITO nanofibers" Sensors Actuators, B Chem., 143(1): 71-75 2009.

24. Munir, MM., F. Iskandar, K. M. Yun, K. Okuyama, M. Abdullah, "Optical and electrical properties of indium tin oxide nanofibers prepared by electrospinning" Nanotechnology, 19(14):145603, 2008.

25. http://www.tibtech.com/conductivity.php. [Accessed: 22-Nov-2017].

26. Gulen, M., G. Yildirim, S. Bal, A. Varilci, I. Belenli, M. Oz, "Role of annealing temperature on microstructural and electro-optical properties of ITO films produced by sputtering" J. Mat. Sci. Mater. Electron., 24:467-74, 2013. 